\title{
PRODUÇÃO E ESTADO NUTRICIONAL DO MILHO EM CULTIVO INTERCALAR COM ADUBOS VERDES ${ }^{(1)}$
}

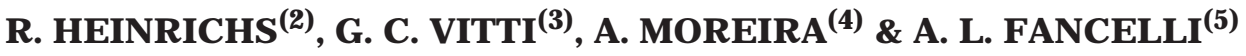

\begin{abstract}
RESUMO
A utilização da adubação verde para estabelecer a diversidade e o equilíbrio do sistema de produção é um dos paradigmas da agricultura moderna. Com o objetivo de avaliar a produção e o estado nutricional da cultura de milho sob cultivo intercalar com adubos verdes, foi realizado, entre 1995 e 1997, um experimento em campo, em Piracicaba (SP), em um Litossolo Vermelho eutrófico. O milho foi semeado no espaçamento de $0,90 \mathrm{~m}$ nas entrelinhas, perfazendo aproximadamente $\mathbf{5 0 . 0 0 0}$ plantas por hectare. Os tratamentos constaram de uma testemunha, sem cultivo intercalar, e quatro espécies de adubos verdes: mucuna anã (Mucuna deeringiana (Bort.) Merr), guandu anão (Cajanus cajan (L.) Millsp), crotalária (Crotalaria spectabilis Roth) e feijão-de-porco (Canavalia ensi formis (L.) DC.), semeados sem adubação, no meio da entrelinha, distante $45 \mathrm{~cm}$ da linha do milho, em duas épocas: simultânea à semeadura do milho e $\mathbf{3 0}$ dias após. $\mathbf{O}$ solo, no primeiro ano, foi preparado sob sistema convencional e, no segundo, cultivaram-se as culturas sob semeadura direta. 0 delineamento experimental foi de blocos ao acaso com parcelas subdivididas e quatro repetições. 0 estado nutricional e a produção de grãos do milho apresentaram melhores resultados no cultivo consorciado com feijão-de-porco. Os efeitos positivos desta espécie na produtividade de grãos de milho foram mais acentuados no segundo ano de adoção do culti vo consorciado, quando o sistema de manejo do solo foi semeadura direta. A semeadura dos adubos verdes simultânea ao milho foi o manejo mais recomendável, por não prejudicar o desenvolvimento do milho e reduzir a operação pós-plantio.
\end{abstract}

Termos de indexação: Zea mays, consorciação, mucuna anã, guandu anão, crotalária, feijão-de-porco.

\footnotetext{
(1) Suporte financeiro FAPESP. Recebido para publicação em outubro de 2000 e aprovado em setembro de 2001.

(2) Doutorando no CENA, Universidade de São Paulo - USP. Caixa Postal 96, CEP 13400-970 Piracicaba (SP). Bolsista da FAPESP. E-mail: regesh@cena.usp.br

(3) Professor do Departamento de Solos e Nutrição de Plantas, Escola Superior de Agricultura Luiz de Queiroz - ESALQ. Caixa Postal 9, CEP 13418-900 Piracicaba (SP).

(4) Engenheiro-Agronômo da Embrapa Amazônia Ocidental. Caixa Postal 319, CEP 69011-970 Manaus (AM). Bolsista DCR/CNPq. E-mail: adonis@cpaa.embrapa.br

(5) Professor do Departamento de Produção Vegetal, ESALQ.
} 


\title{
SUMMARY: MAIZE PRODUCTION AND NUTRITIONAL STATE IN GREEN MANURE INTERCROPPED SYSTEM
}

\begin{abstract}
Theuse of green manureto establish diversity and equilibrium of a crop system is one of theparagons in modern agriculture Soil samples and green manurespecies intercropped with maize were evaluated in a field experiment, from 1995 to 1997, carried out in an Aleudalf Soil, located in Piracicaba (SP). Maize seeds were planted at 0.90 meter spacing within lines total ing 50,000 plants per hectare. The treatments were performed with four green manure species: dwarf mucuna (Mucuna deeringiana (Bort.) Merr), dwarf pigean pea (Cajanus cajan (L.) Millisp), crotalaria (Crotalaria spectabilis Roth), jack beans (Canavalia ensiformis (L.) DC.), and a control treatment without green manure Seeds of green manurespecies wereplanted between maizelines at $45 \mathrm{~cm}$ distancewithout fertilization simultaneousl y with maizeand 30 days after maizeplanting. In thefirst year, thesoil was prepared under a conventional system; in the second year, cultivation was seedl ing under no till age system, using randomized blocks in a split plot design with four replicates. The nutritional status and grain production of maize showed the best results in the system intercropped with jack beans. Thepositive effects of this species on maize productivity were more evident in the second year of the intercropped system, with seedling under no tillage system. The simultaneous planting of maize and green manure species is the most recommended management practice, because maize growth is not affected by any other planting activities.
\end{abstract}

Index terms: Zea mays, intercropping, dwarf mucuna, dwarf pigean pea, crotalaria, jack beans.

\section{NTRODUÇÃO}

O milho, embora constitua um dos principais cereais do segmento produtivo agrícola no Brasil, apresenta, ainda, baixa produtividade, em torno de $2.700 \mathrm{~kg} \mathrm{ha}^{-1}$ (IBGE, 1998), e elevados custos de produção. Essa baixa produtividadeestá relacionada, em parte, com o baixo nível tecnológico empregado na produção. O uso de sementes certificadas, de adubação e agrotóxicos é significativamente menor na cultura do milho $(21,8 \%)$ do que, por exemplo, na cultura da soja $(71,4 \%)$, comparando a área total plantada (EMBRAPA, 1997).

Neste contexto, aumentar a produção agrícola, considerando a capacidade de assimilação da natureza e conservando os recursos naturais, é o paradigma preconizado para o desenvolvimento sustentável dos agroecossistemas. Segundo Heinrichs (1996), a adubação verde é uma das práticas viáveis para a contribuição no restabelecimento do equilíbrio do sistema eaumento da produtividade.

A importância da adubação ver de na reciclagem de nutrientes é relatada por Sarrantonio \& Scott (1988) e Ros et al. (1996). Para Tanaka (1981), as leguminosas são mais adequadas para adubação verde, por terem um rendimento el evado de fitomassa por área e por serem ricas em nutrientes, já que o seu sistema radicular, bastante ramificado e profundo, permite recuperar os nutrientes lixiviados para camadas mais profundas do solo. No entanto, Muzilli (1986) ressalta que a composição química dos adubos verdes é variável segundo características inerentes à própria espécie, tais como: idade, condições edáficas e fatores climáticos reinantes no período.

Segundo Mascarenhas \& Tanaka (1993), a época do cultivo do adubo verde é de fundamental importância para não concorrer com a cultura comercial. Assim, a consorciação de aduboverde com a cultura econômica poderia trazer a soluç̧ão desse problema, quando o uso da terra for intensivo. Os efeitos benéficos da consorciação na produção de grãos foram observados por Alvarenga (1995), podendo proporcionar para o sistema agrícola as seguintes vantagens: aumento da produção de matéria seca, maior cobertura do solo durante o período de desenvol vimento da cultura, reciclagem e disponibilidade de nutrientes.

O presente trabalho teve por objetivo avaliar o estado nutricional e a produção do milho quando submetido ao cultivo intercalar com adubos verdes.

\section{MATERIAL E MÉTODOS}

O experimento foi realizado em campo, durante os anos agrícolas 1995/96 e 1996/97, na área experimental pertencente à Escola Superior de Agricultura "Luiz de Queiroz"/Universidade de São Paulo, Piracicaba (SP), Brasil, localizado nas coordenadas 22\%42'30" latitude sul e 47038'00" longitude oeste, em um Litossol oVermel ho eutrófico. 
O milho (BRASKALB XL 660) foi semeado no espaçamento de $0,90 \mathrm{~m}$ nas entrelinhas, perfazendo

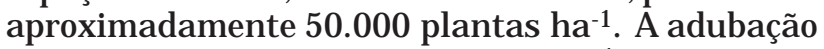
no sulco desemeadura foi de $30 \mathrm{~kg} \mathrm{ha}^{-1}$ de N (uréia), $72 \mathrm{~kg} \mathrm{ha}^{-1}$ de $\mathrm{P}_{2} \mathrm{O}_{5}$ (superfosfato triplo) e $48 \mathrm{~kg} \mathrm{ha}^{-1}$ de $\mathrm{K}_{2} \mathrm{O}$ (cloreto de potássio). As sementes de milho foram tratadas com inseticida, grupo químico carbamato (Futur 300), quecontinha produtos à base de zinco ( $\left.250 \mathrm{~g} \mathrm{~L}^{-1}\right)$, molibdênio $\left(10 \mathrm{~g} \mathrm{~L}^{-1}\right)$ e boro $\left(2 \mathrm{~g} \mathrm{~L}^{-1}\right)$. A adubação de cobertura no milho foi de $90 \mathrm{~kg} \mathrm{ha}^{-1}$ de nitrogênio na forma de uréia, o qual foi aplicado no estádio deoito fol has. Os tratamentos constaram de uma testemunha, sem cultivo intercalar, e quatro espécies de adubos verdes, semeadas sem adubação, no meio da entrelinha, ficando distanciadas $45 \mathrm{~cm}$ da linha do milho, em duas épocas: simultânea à semeadura do milho e 30 dias após (Quadro 1).

O delineamento experimental foi em blocos ao acaso com parcelas subdividi das e quatro repeti ções. Cada parcela constituía $9 \times 12 \mathrm{~m}$ e as subparcelas $4,5 \times 12 \mathrm{~m}$. O solo foi preparado pelo sistema convencional, com uma aração profunda e duas gradagens. No segundo ano agrícola, as culturas foram instaladas no sistema de semeadura direta.

A amostragem para avaliação da produção de fitomassa e acúmulo de nutrientes foi realizada na fase da emissão dos estilos-estigmas. Col etaram-se três plantas por subparcela, secas em estufa a $70^{\circ} \mathrm{C}$ até peso constante. Para avaliar o estado nutricional pela técnica da diagnose foliar (Malavolta et al., 1997), coletaram-se 10 folhas por subparcela, utilizando-se o terço médio com a exclusão da nervura central, sendo a fol ha amostrada imediatamente abaixo da espiga superior, na época da emissão dos estilos-estigmas (Cantarella et al., 1996). A pós a secagem, as amostras foram moídas para a determinação dos teores de nitrogênio, fósforo, potássio, cálcio, magnésio e enxofre, segundo o método descrito por Malavolta et al. (1997). Para avaliar a produção de grãos, o milho foi colhido, manualmente, quando estes encontravam-se em estádio de grãos secos.
Os resultados foram submetidos à análise de variância, teste $F$ e contraste entre médias, usando o teste destudent a 5\% (Banzatto \& Kronka, 1995).

\section{RESULTADOS E DISCUSSÃO}

No quadro 2, encontram-se os teores de macronutrientes nas fol has do milho. Observou-se diferença nos teores de $\mathrm{N}$ somente no segundo ano de cultivo do milho, quando os tratamentos com adubo verde diferiram da testemunha, exceto os tratamentos mucuna anã semeada 30 dias após o milho (MA-B) e guandu anão si multâneo com o milho (GA-A).

Tal resultado evidencia que a adubação verde contribuiu para nutrição da cultura em sucessão, no entanto, no mesmo ciclo, sua influência foi muito pequena. Os tratamentos com feijão-de-porco (FP) diferiram positivamente dos demais tratamentos com adubação ver de, exceto do tratamento mucuna anã semeada simultânea ao milho (MA-A), ressaltando-se a importância do adubo verde na nutrição nitrogenada, como fora relatado por Sarrantonio \& Scott (1988) e Ros et al. (1996). No segundo ano agrícola, obtiveram-se menores teores de $\mathrm{N}$, possivelmente decorrente da imobilização causada pela decomposição da palhada de milho do primeiro ano (Sá, 1993).

Os teores de fósforo nas fol has do mil ho revelaram diferenças somente no segundo ano de cultivo, tendo os tratamentos com feijão-de-porco apresentado maior teor em relação à testemunha e aos demais tratamentos com adubação ver de (Quadro 2). E sta espécie produziu maior quantidade de matéria seca e, conseqüentemente, maior acúmulo de nutrientes, contribuindo, dessa forma, para maior disponibilidade e reciclagem dos nutrientes. Os teores de potássio, cálcio, magnésio e enxofre não diferiram entre os tratamentos.

\section{Quadro 1. Tratamentos estudados no consórcio milho e adubo verde}

\begin{tabular}{clcc}
\hline Tratamento & \multicolumn{1}{c}{ Adubo verde } & Plantas & É poca de semeadura \\
\hline & & $\mathrm{no} \mathrm{m} \mathrm{m}^{-1}$ & \\
Testemunha & Sem adubo verde intercalar & 10 & Simultânea com o milho \\
MA-A & Mucuna anã (Mucuna deeringiana (Bort.) Merr) & 10 & 30 dias após o milho \\
MA-B & Mucuna anã (Mucuna deeringiana (Bort.) Merr) & 20 & Simultânea com o milho \\
GA-A & Guandu anão var. IAPAR 43 aratã (Cajanus cajan (L.) Millsk & 30 dias após o milho \\
GA-B & Guandu anão var. IAPAR 43 aratã (Cajanus cajan (L.) Millsk & 20 & Simultânea com o milho \\
CS-A & Crotalaria spectabilis Roth & 20 & 30 dias após o milho \\
CS-B & Crotalaria spectabilis Roth & 20 & Simultânea com o milho \\
FP-A & Feijão-de-porco (Canavalia ensiformis (L.) DC.) & 10 & 30 dias após o milho \\
FP-B & Feijão-de-porco (Canavalia ensiformis (L.) DC.) & 10 &
\end{tabular}


Quanto à faixa de teores adequados, observa-se (Quadro 2) que os teores de $\mathrm{N}$ estão na faixa adequada de 27 a $35 \mathrm{~g} \mathrm{~kg}^{-1}$, indicada por Cantarella et al. (1996) em todos tratamentos no primeiro ano de cultivo e no segundo apenas com feijão-de-porco. O mesmo ocorrecom fósforo, potássio, cálcioe enxofre para todos os tratamentos, respectivamente, 2,0 a 4,0, 17 a 35, 2,5 a 8,0 e 1,5 a 3,0 $\mathrm{g} \mathrm{kg}^{-1}$. O magnésio, exceto nos tratamentos com guandu anão no segundo ano (GA-A e GA-B), também está na faixa considerada adequada, 1,5 a 5,0 $\mathrm{g} \mathrm{kg}^{-1}$ (Cantarella et al., 1996).

No primeiro ano agrícola, observou-se que a produção de matéria verde de milho foi maior nos tratamentos feijão-de-porco semeado 30 dias após o milho (FP-B) e Crotalaria spectabilis simultânea com o milho (CS-A), com valores, respectivamente, de 32 e $30 \%$ superiores aos dotratamento sem cultivo intercalar de adubo verde (Quadro 3).
No segundo ano agrícola, apesar de todos os tratamentos, exceto GA-B, terem apresentado maior produção de matéria verde do que a testemunha, apenas o tratamento com feijão-de-porco semeado simultâneo com milho (FP-A) mostrou diferença significativa, na ordem de $20 \%$. Os efeitos benéficos do feijão-de-porco foram observados nitidamenteem campo, pois ele apresentou melhor adaptação às condições de luz difusa, confirmando relatos de Monegat (1991). A produção de matéria seca não apresentou diferenças significativas entre os tratamentos (Quadro 3); entretanto, no feijão-deporco (FP-A), ocorreram maiores produções no primeiro e no segundo cultivo, em relação à testemunha, com 18 e $11 \%$ de acréscimo, respectivamente.

O acúmulo de macronutrientes na parte aérea das plantas de milho no estádio da emissão dos estilos-estigmas não apresentou efeito significativo

Quadro 2. Teores de macronutrientes nas folhas do milho usadas para diagnose no estádio de emissão dos esti los-estigmas (anos agrícolas 1995/96 e 1996/97) ${ }^{(1)}$

\begin{tabular}{|c|c|c|c|c|c|c|c|c|c|c|c|c|}
\hline \multirow{2}{*}{ Tratamento } & \multicolumn{2}{|c|}{$\mathbf{N}$} & \multicolumn{2}{|c|}{$\mathbf{P}$} & \multicolumn{2}{|c|}{$\mathbf{K}$} & \multicolumn{2}{|c|}{$\mathrm{Ca}$} & \multicolumn{2}{|c|}{ Mg } & \multicolumn{2}{|c|}{$\mathbf{S}$} \\
\hline & 1995/96 & 1996/97 & $1995 / 96$ & 1996/97 & 1995/96 & 1996/97 & 1995/96 & 1996/97 & $1995 / 96$ & $1996 / 97$ & $1995 / 96$ & 1996/97 \\
\hline Testemunha & 29,5 & $21,3 \mathrm{e}$ & 3,0 & $2,9 c$ & 228 & 219 & 40 & 4.5 & 17 & 15 & 18 & 18 \\
\hline MA-A & 27,7 & $26,2 \mathrm{ab}$ & 3,0 & $3,2 \mathrm{~b}$ & 23,8 & 23,3 & 3,7 & 4,9 & $\begin{array}{l}1,1 \\
1,6\end{array}$ & $\begin{array}{l}1,3 \\
1,8\end{array}$ & $\begin{array}{l}1,0 \\
1,8\end{array}$ & $\begin{array}{l}1,0 \\
1,9\end{array}$ \\
\hline$M A-B$ & 28,4 & $22,1 \mathrm{e}$ & 3,2 & $2,9 \mathrm{c}$ & 24,7 & 22,3 & 3,8 & 4,1 & 1,7 & 1,5 & 1,9 & 1,8 \\
\hline GA-A & 28,2 & $22,3 \mathrm{de}$ & 3,1 & $2,8 \mathrm{c}$ & 24,0 & 20,0 & 4,1 & 4,3 & 1,7 & 1,3 & 1,8 & 1,8 \\
\hline GA-B & 28,5 & $23,0 \mathrm{~cd}$ & 3,1 & 3,0 bc & 24,7 & 21,6 & 3,8 & 4,0 & 1,7 & 1,4 & 1,7 & 1,9 \\
\hline CS-A & 29,1 & $24,2 \mathrm{~cd}$ & 3,2 & $3,0 \mathrm{bc}$ & 24,6 & 22,3 & 4,0 & 4,8 & 1,7 & 1,7 & 1,5 & 1,8 \\
\hline CS-B & 29,3 & 24,4 bc & 3,2 & $3,2 \mathrm{~b}$ & 25,6 & 22,9 & 3,7 & 4,5 & 1,7 & 1,6 & 1,9 & 1,9 \\
\hline F P -A & 28,6 & $27,5 \mathrm{a}$ & 3,2 & $3,6 \mathrm{a}$ & 24,6 & 22,0 & 3,6 & 4,9 & 1,7 & 1,7 & 1,5 & 2,0 \\
\hline$F P-B$ & 28,5 & 27,5 a & 3,2 & $3,5 \mathrm{a}$ & 24,3 & 20,0 & 3,7 & 4,8 & 1,7 & 1,8 & 1,7 & 2,1 \\
\hline C.V. (\%) & 4 & 5 & 5 & 6 & 4 & 4 & 11 & 11 & 9 & 11 & 8 & 8 \\
\hline
\end{tabular}

(1) Médias seguidas da mesma letra não diferem significativamente entre si pelo teste Student a 5\%.

Quadro 3. Produção de matéria seca e verde das plantas de milho (anos agrícolas 1995/96 e 1996/97)(1)

\begin{tabular}{|c|c|c|c|c|}
\hline \multirow{2}{*}{ Tratamento } & \multicolumn{2}{|c|}{ Matéria verde } & \multicolumn{2}{|c|}{ Matéria seca } \\
\hline & 1995/96 & 1996/97 & 1995/96 & 1996/97 \\
\hline & \multicolumn{4}{|c|}{$-\mathrm{kg} \mathrm{ha}^{-1}$} \\
\hline Testemunha & $53.031 \mathrm{c}$ & $50.264 \mathrm{~b}$ & 13.519 & 9.845 \\
\hline MA-A & $52.939 \mathrm{c}$ & $54.507 a b$ & 13.872 & 10.610 \\
\hline MA-B & 56.347 bc & $52.483 a b$ & 13.523 & 10.445 \\
\hline GA-A & 62.822 abc & $53.528 a b$ & 15.219 & 10.265 \\
\hline GA-B & $64.063 \mathrm{abc}$ & $46.804 \mathrm{~b}$ & 13.944 & 9.169 \\
\hline CS-A & $68.776 \mathrm{ab}$ & $52.613 a b$ & 14.959 & 10.866 \\
\hline CS-B & $60.015 a b c$ & $52.222 a b$ & 15.513 & 9.883 \\
\hline FP-A & $61.817 \mathrm{abc}$ & $60.316 a$ & 15.917 & 10.934 \\
\hline FP-B & $69.924 \mathrm{a}$ & $51.699 a b$ & 16.280 & 10.829 \\
\hline C.V. (\%) & 14 & 11 & 22 & 13 \\
\hline
\end{tabular}

(1) Médias seguidas da mesma letra não diferem significativamente entre si pelo teste Student a 5\%. 
dos tratamentos (Quadro 4). Na comparação dos dois anos agrícolas, verificou-se que todos os nutrientes apresentaram maior acúmulo no primeiroano, sendo um reflexo da maior produção de fitomassa do milho naqueleano (Quadro 3). As maiores diferenças entre os anos de cultivo foram observadas no nitrogênio, possivelmente em decorrência do efeito da imobilização do nutriente para decomposição da palhada de milho. Segundo Sá (1993) e Castro (1996), na semeadura direta, a decomposição dos restos vegetais é mais lenta que nos sol os preparados pelo método convencional, no qual a liberação dos nutrientes é acelerada.

No peso de mil grãos, não houve efeito significativo dos tratamentos no primeiro ano de cultivo, porém, no segundo ano, o tratamento com feijão-de-porco, semeado simultaneamente com o milho (FP-A), apresentou maior média, não diferindo dos tratamentos FP-B e CS-B (Quadro 5). O rendimento de grãos apresentou efeito dos tratamentos somente no segundo ano de cultivo, concordando com Vieira (1961). O cultivo intercalar de feijão-de-porco, semeado simultaneamente e 30 dias após o milho, proporcionou aumento na produção de grãos em relação à testemunha, de $24 \mathrm{e}$ $16 \%$, respectivamente. Estes resultados discordam dos de Skóra Neto (1993), que encontrou menor rendimento no sistema consorciado simultâneo, justificado por uma possível competição entre a leguminosa e o milho na fase inicial.

Comparando os dois anos de cultivo, verificou-se que o feijão-de-porco semeado simultâneo e 30 dias após o milho (FP-A e FP-B) apresentou acréscimo de 32 e 14\%, respectivamente, no rendimento de grãos no segundo ano em relação ao primeiro (Quadro 5). A utilização da cultura do milho em sistema consorciado concordou com os resultados encontrados por Alvarenga (1995) que relata

Quadro 4. Acúmulo de macronutrientes na parte aérea das plantas de milho no estádio de emissão dos estilos-estigmas (anos agrícolas 1995/96 e 1996/97) ${ }^{(1)}$

\begin{tabular}{|c|c|c|c|c|c|c|c|c|c|c|c|c|}
\hline \multirow{2}{*}{ Tratamento } & \multicolumn{2}{|c|}{$\mathbf{N}$} & \multicolumn{2}{|c|}{$\mathbf{P}$} & \multicolumn{2}{|c|}{$\mathbf{K}$} & \multicolumn{2}{|c|}{$\mathrm{Ca}$} & \multicolumn{2}{|c|}{ Mg } & \multicolumn{2}{|c|}{$\mathbf{S}$} \\
\hline & 1995/96 & $1996 / 97$ & 1995/96 & 1996/97 & 1995/96 & 1996/97 & 1995/96 & 1996/97 & 1995/96 & 1996/97 & 1995/96 & 1996/97 \\
\hline & \multicolumn{12}{|c|}{ - $\mathrm{kg} \mathrm{ha}^{-1}$} \\
\hline Testemunha & 222 & $89 a b$ & 22 & 17 & 288 & 202 & 43 & 24 & 28 & 14 & 16 & 10 \\
\hline$M A-A$ & 234 & $93 a b$ & 22 & 17 & 275 & 215 & 33 & 29 & 26 & 15 & 10 & 10 \\
\hline MA-B & 235 & $99 a b$ & 26 & 18 & 273 & 217 & 39 & 26 & 28 & 13 & 15 & 10 \\
\hline GA-A & 231 & $92 a b$ & 24 & 18 & 297 & 228 & 49 & 25 & 27 & 14 & 12 & 10 \\
\hline GA-B & 238 & $73 b$ & 26 & 18 & 298 & 192 & 32 & 22 & 22 & 13 & 12 & 8 \\
\hline CS-A & 230 & $85 b$ & 25 & 20 & 326 & 219 & 49 & 25 & 36 & 14 & 10 & 9 \\
\hline CS-B & 242 & $95 a b$ & 25 & 19 & 306 & 220 & 29 & 21 & 26 & 13 & 12 & 9 \\
\hline F P-A & 230 & $112 a$ & 27 & 24 & 355 & 239 & 33 & 30 & 29 & 17 & 14 & 12 \\
\hline FP-B & 273 & $95 a b$ & 31 & 20 & 311 & 219 & 41 & 23 & 33 & 15 & 16 & 8 \\
\hline C.V. (\%) & 25 & 19 & 26 & 18 & 21 & 11 & 28 & 17 & 26 & 20 & 30 & 20 \\
\hline
\end{tabular}

(1) Médias seguidas da mesma letra não diferem significativamente entre si pelo teste Student a 5\%.

Quadro 5. Peso demil grãos e rendimento degrãos de mi lho a 13\%de umidade (anos agrícolas 1995/96e 1996/97) ${ }^{(1)}$

\begin{tabular}{|c|c|c|c|c|c|c|}
\hline \multirow{2}{*}{ Tratamento } & \multicolumn{2}{|c|}{1.000 grãos } & \multicolumn{4}{|c|}{ Rendimento de grão } \\
\hline & 1995/96 & 1996/97 & 1995/96 & relativo & 1996/97 & relativo \\
\hline & 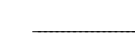 & - & kg ha-1 & $\%$ & $\mathrm{~kg} \mathrm{ha}^{-1}$ & $\%$ \\
\hline Testemunha & 319,4 & $305,6 b c$ & 6.209 & 100 & $6.078 b$ & 100 \\
\hline MA-A & 329,5 & $300,0 c$ & 5.798 & 93 & $5.704 b$ & 94 \\
\hline MA-B & 313,8 & $305,0 c$ & 5.767 & 93 & $5.861 b$ & 96 \\
\hline GA-A & 319,7 & $301,3 c$ & 5.676 & 91 & $5.815 b$ & 96 \\
\hline GA-B & 319,1 & $306,6 b c$ & 5.863 & 94 & $5.860 \mathrm{~b}$ & 96 \\
\hline CS-A & 318,8 & $306,5 b c$ & 6.154 & 99 & $5.680 \mathrm{~b}$ & 93 \\
\hline CS-B & 321,9 & $310,1 a b c$ & 6.244 & 100 & $5.817 \mathrm{~b}$ & 96 \\
\hline FP-A & 320,4 & $322,4 a$ & 5.676 & 91 & $7.548 a$ & 124 \\
\hline FP-B & 319,3 & $319,7 a b$ & 6.172 & 99 & 7.067a & 116 \\
\hline C.V. (\%) & 2 & 3 & 7 & & 6 & \\
\hline
\end{tabular}

(1) Médias seguidas da mesma letra não diferem significativamente entre si pelo teste Student a 5\%. 
aumento de produção em relação à monocultura. Cabe salientar que o sistema proposto não atrapal ha a colheita mecânica, já que o feijão-de-porco apresenta hábito de crescimento prostrado. A partir desses resultados, pode-se observar o potencial do feijão-de-porco para cultivo intercalar com o milho, aumentando os efeitos benéficos sobre esta cultura com o aumento do período de cultivo. Torna-se necessário, no entanto, desenvol ver semeadoras com mecanismo adaptado para espécies com sementes grandes, como é o caso do feijão-de-porco.

\section{CONCLUSÕES}

1. A semeadura dos adubos verdes simultânea com o milho foi a prática mais recomendável, pois o estado nutricional ea produção de grãos da gramínea não foram prejudicados e reduziram a operação pósplantio.

2. Os efeitos positivos do feijão-de-porco na produção de grãos de milho foram mais acentuados no segundo ano de adoção do cultivo consorciado.

\section{LITE RATURA CITADA}

ALVARENGA, D.A. Efeitos de diferentes sistemas de semeadura na consorciação milho-soja. Lavras, Universidade Federal de 1995. 46p. (Tese de Mestrado)

BANZATTO, P.A. \& KRONKA, S.N. Experimentação agrícola. J aboticabal, Fundação de Estudos e Pesquisas em Agronomia, Medicina Veterinária e Zootecnia, 1995. 247p.

CANTARELLA, H.; RAIJ , B. van \& CAMARGO, C.E.O. 13 cereais. In: RAIJ , B. van; CANTARELLA, H.; QUAGGIO, J.O. \& FURLANI, A.M.C., eds. Recomendações de adubação e calagem para o estado de São Paulo. Campinas: Instituto Agronômico \& Fundação, 1996. p.43-71. (Boletim técnico, 100)

CASTRO, O.M. Comportamento físico equímico de um Latossolo roxo em função do seu preparo na cultura do milho (Zea mays L.). Piracicaba, Escola Superior de Agricultura "Luiz de Queiroz" 1995. 174p. (Tese de Doutorado)
EMPRESA BRASILEIRA DE PESQUISA AGROPECUÁRIA EMBRAPA. Centro de Pesquisa Agropecuária do Oeste. Milho: informações técnicas. Dourados, 1997. 222p. (Circular Técnica, 5)

HEINRICHS, R. Ervilhaca e aveia preta cultivadas simultaneamente como adubo verde e sua influência no rendimento do milho. Piracicaba, Escola Superior de Agricultura "Luiz de Queiroz", 1996. 65p. (Tese de Mestrado)

INSTITUTO BRASILEIRO DE GEOGRAFIA E ESTATISTICA - IBGE. Anuário Estatístico do Brasil. Rio de J aneiro, 58:3-31, 1998.

MALAVOLTA, E.; VITTI, G.C. \& OLIVEIRA, S.A. Avaliação do estado nutricional das plantas: princípios e aplicações. Piracicaba, Associação Brasileira para Pesquisa da Potassa e do Fosfato, 1997. 319p.

MASCARENHAS, H.A.A. \& TANAKA R.T. Rotação de culturas. In: CURSO SOBRE ADUBAÇÃO VERDE NO INSTITUTO AGRONÔMICO, 1., Campinas, 1993. p.71-86. (Documentos IAC35)

MONEGAT, C. Plantas de cobertura do solo: Características e manejo em pequenas propriedades. Chapecó, Edição do Autor, 1991. 337p.

MUZI LLI, O. Adubação verde como alternativa para a mel horia da fertilidade do sol o eracional ização do uso de fertilizantes. Inf. Pesq. IAPAR, 10:1-4, 1986.

ROS, C.O. \& AITA, C. Efeito de espécies de inverno na cobertura do solo e fornecimento de nitrogênio ao milho em plantio direto. R. Bras. Ci. Solo, 20:135-140, 1996.

SÁ,J .C.M. Manejo da fertilidade do sol o no plantio direto. Castro, Fundação ABC, 1993. 93p.

SARRANTONIO, M. \& SCOTT,T.W. Tillage effects on availability of nitrogen to corn following a winter green manure crop. Soil Sci. Soc. Am. J., 52:1661-1668, 1988.

SKÓRA NETO, F. Controle de plantas daninhas através de coberturas verdes consorciadas com milho. Pesq. Agropec. Bras., 28:1165-1170, 1993.

TANAKA, R.T. Adubação verde. Inf. Agropec., 7:62-67, 1981.

VIEIRA, C. Efeito da adubação verde intercalar sobre o rendimento do milho. Experientiae, 1:1-24, 1961. 